\title{
USING DIGITAL TOOLS TO ENGAGE KENYAN DEVELOPMENT STUDENTS WITH DATA
}

\author{
Giovanna De Giusti \\ Maseno University, Kenya \\ Giovanna.degiusti@gmail.com
}

This paper describes the use of innovative tools for teaching research methods to undergraduate students in Development Studies and Political Sciences in Kenya. These tools included open educational resources such as those available in Computer-Assisted Statistics Textbooks and Statistics Made Simple. Such resources, rooted in practical examples and real-life scenarios, enabled students understanding theoretical concepts through their application. Open Data Kit, an opensource suite of tools that enables the design of surveys, data collection through mobile devices and data submission to an online server, was used to provide the students with practical experience. These tools can be used to transform teaching and provide graduates with the practical skills required in the field of development. Moreover, they can be successfully deployed in resource-poor environments like Kenya, where relatively few students have access to laptops or computers and the internet connectivity is relatively low, but most have access to mobile devices.

\section{INTRODUCTION}

Development as field of study has moved on as evidence has become more and more important, and data is nowadays essential in decision-making processes. However, there is a gap between the current unprecedented availability of data and the skills required to interpret and manage it, and to improve its quality. It is important to build graduates' statistical literacy and the research skills needed for development.

The need to modernize statistics education and more broadly the teaching of research methods in Kenya has been recognised for many years. At all levels, learning is still primarily theorybased, and characterised by reading selected textbooks and taking notes regularly, and the emphasis is on mathematical formulae. Bringing technology into education provides the opportunity to change the way of teaching (Manyalla, Mbasu, Stern \& Stern, 2014).

This paper describes the use of innovative open tools for teaching quantitative research methods to 116 third year undergraduate students in Development Studies and Political Sciences in Maseno University, Kenya. The research methods course at the School of Development and Strategic Studies in Maseno University is designed for third year students in Development Studies and Political Sciences. At the end of their third year, these students are required to spend three months in industrial attachment at a private, public or non-profit organisation, and during that time they must chose a research topic, design a study, collect data and perform simple analysis. This work leads to a dissertation which is the requirement of a module called Research Project to be completed at the beginning of their fourth year. The research methods course should therefore provide the students with the knowledge and skills needed to carry out such research project, while also enabling them to acquire basic skills to be used in their research and work later on in their career.

A term in Maseno consists of ten weeks, of which eight can have effective teaching (two weeks being used to sort administrative stuff at the beginning of the term), and each week consists of four hours teaching. When the author took over the teaching of research methods, the course was purely theory-based and lacked an applied perspective that would enable the students to grasp concepts and use them in their research and work. The author was conscious of the need to integrate into the teaching materials and tools that could provide a practical approach to the subject.

The tools used in the teaching, based on Information and Communication Technologies, involved an applied, hands-on, data-focused approach, and enabled transforming a traditional course, previously taught theoretically, and enabling the students to build the practical skills required to do research and work in the development field.

Having previously taken Statistics Made Simple (e-SMS), an on-line open course given by the University of Reading and facilitated by Maseno University, the author decided to integrate it in her teaching. This was designed to be used together with a custom CAST e-book (Computer-Assisted Statistics Textbooks) (Stirling, 2005). Both tools were used by the lecturer in class by mean of a 
laptop and a projector; all materials had been previously downloaded and could be used off-line. Previous experience working with Open Data Kit (ODK) convinced the author of the high demand for skills in the use of this tool and the need for students to acquire such skills, and ODK was therefore included among the teaching tools. All the materials were accessed by the students mainly through mobile phones. Several software were used for simple data analysis. Finally, a Whatsapp group was created to share knowledge and continue and support the learning out of class.

\section{THE TOOLS}

$e-S M S$

e-SMS is an innovative programme designed as an e-Learning course by the University of Reading for those who are starting their research, or who are involved in development projects involving data collection and analysis, and want to build their research skills. The programme is intended to provide the students with the core skills required for statistical analysis. As such, it is rooted in practical examples and real-life scenarios, and the emphasis is more on ideas and interpretation than on theory and formulas.

e-SMS includes ten topics; the author used materials from the first four, including: 1) a brief introduction to e-SMS; 2) descriptive statistics; 3) simple statistical inference; and 4) hypothesis testing. These four topics therefore provide key transferable skills in statistics, specifically in understanding, describing and quantifying variability. They cover both descriptive and inferential techniques for analysing sample data, the concept of hypothesis testing, how to interpret p-values and the difference between statistical significance and practical importance.

\section{CAST}

CAST (Stirling, 2005) was introduced to Maseno University's postgraduate students in 2008 (Stern, Stirling, \& Stern, 2009). It consists of a set of electronic books, which cover introductory and more advance topics in statistics, and has a number of strengths over standard statistics textbooks. First, it has a practical focus, employing data and scenarios from different application areas (business, biometry etc.). Difficult concepts are explained using dynamic displays, i.e. graphics, animations and simulations. It is interactive, to keep interest high and enable independent work by the students. Finally, it includes a set of computer-based exercises that represent a particularly effective form of active learning since they make students think and recall information (Stern, Stirling, Dale \& Stern, 2010).

The effectiveness of the exercises comes from the fact that they include a "Tell me" button (if a student does not know how to do a task, the computer provides the correct response) and the "Another question" button, which randomises as many aspects of the question as possible, including the context and data sets. This allows the student to repeat an exercise until they have really understood the concepts (Stern, Stirling, Dale \& Stern, 2010).

Previous studies have shown that student motivation and performance are both improved by the adoption of CAST (Manyalla, Mbasu, Stern \& Stern, 2014), and have demonstrated the effectiveness of the exercises (Stern, Stirling, Dale \& Stern, 2010). CAST allows a trainer to adapt and create her own e-book, and the e-book employed in the research methods course was created to be used in parallel with e-SMS. Adapted CAST exercises were used as a part of the continuous assessment tests carried out in the course of the semester.

e-SMS and CAST occupied the students for four out of eight weeks of teaching, for six hours a week: four hours of regular teaching and two hours added upon request by the students who wanted to deepen the understanding of the concepts through further discussions and practical exercises.

$O D K$

Open Data Kit (ODK) is a suite of tools that allows data collection using Android mobile devices and data submission to an online server, even without an Internet connection or mobile carrier service at the time of data collection. It enables use of a variety of data types, allowing users to attach GPS points, photos and videos to surveys.

A young researcher was invited as guest speaker and facilitator to introduce to the class ODK, its advantages over traditional data collection methods and how it works. After this 
introduction, ODK was employed in the course of a practical that aimed at building the skills needed to design a survey, collect data and perform basic analysis. The task, carried out over four weeks, was centred around a gender study, where the students were required to investigate the existence and extent of gender disparities in their community.

In a first stage of the work, the class discussed with the lecturer the purpose of the study and defined a number of possible research questions. They subsequently worked either in groups or individually to design a short survey based on one or more of these questions. After receiving feedback on their survey, they started using ODK. They proceeded to download the "ODK Collect" app from Google Play on their mobile devices, and then learnt to create data collection forms for ODK, mainly using spreadsheets. The latter method was preferred by the author over others (e.g. ODK Build) as it enables the students to build basic programming skills. The students then created their own servers, where they uploaded their forms. Uploading forms is only possible when forms are clear from errors, and this process enabled them to learn how to be precise in the use of simple programming language and accurate in following rules.

Once the survey was uploaded and ready to be used on the phones, the students carried out a short pilot to test their questionnaires. The data collected was viewed to assess basic data quality and improve data collection. Once the final version was ready, the students carried out data collection and eventually simple analysis. Given the time constraints, data collection and analysis were performed by the students on voluntary basis and the students undertaking this task decided to work in groups mainly out of class.

\section{Statistical software}

The course aimed at integrating the use of computers for statistical work, and a number of components were included to achieve this objective. To start with, the students were recommended to carry out the e-SMS practical exercises. These exercises are written for a number of statistical software, including Genstat, Instat, and R. Given the limited access to laptops or personal computers, the students were asked to carry out the exercises on voluntary basis. Also, the students mainly used Instat, a free and general statistical package that provides a relatively gentle introduction to using statistics packages. Commercial statistical software (like for instance SPSS) was used to a very limited extent due to its commercial nature. $\mathrm{R}$ was not used because it requires programming skills.

Also, the students were provided with a large dataset downloaded by the lecturer from the Kenya Demographic and Health Surveys, a nationally representative dataset on demographic and health indicators for the Kenyan population, which they used to investigate the structure of a dataset and -looking at the questionnaires also available in the internet- helped them appreciating the link between data collection tools and final datasets.

Finally, the students carried out basic analysis of the data on gender disparities collected as part of the practical using ODK. The data was first downloaded from the server and then analysed using Excel or Open Office. In particular, pivot tables and pivot charts enabled the students to deepen their analytical skills, by allowing them to easily manipulate and describe data through generating tables, charts and graphs, and assess trends and relationships between numbers. 


\section{DISCUSSION}

Table 1 below briefly describes the tools introduced, summarising their function and the benefits of using them into the course.

\begin{tabular}{|c|c|c|c|}
\hline Tool & Use & Benefits & Limitations \\
\hline e-SMS & $\begin{array}{l}\text { eLearning course. } \\
\text { Used to provide the } \\
\text { structure of the course. }\end{array}$ & $\begin{array}{l}\text { - provide the students with the core } \\
\text { skills required for statistical } \\
\text { analysis } \\
\text { - emphasis on ideas and } \\
\text { interpretation } \\
\text { - enable understanding of the } \\
\text { concepts and the ability to apply } \\
\text { them in research and work } \\
\text { - enable experiencing independent } \\
\text { learning } \\
\text { - prompt sharing and collaboration } \\
\text { - can be downloaded and accessed } \\
\text { through mobile phones }\end{array}$ & \\
\hline CAST & $\begin{array}{l}\text { Tailored e-book. } \\
\text { Used to accompany } \\
\text { eSMS. }\end{array}$ & $\begin{array}{l}\text { - has a practical focus, employing } \\
\text { data and scenarios from different } \\
\text { application areas } \\
\text { - difficult concepts are explained } \\
\text { using dynamic displays } \\
\text { (graphics, } \\
\text { simulations) } \\
\text {-interactive, to keep interest high } \\
\text { and enable independent work by } \\
\text { the students } \\
\text { - computer-based exercises enable } \\
\text { active learning, making students } \\
\text { think and recall information } \\
\text {-can be downloaded and accessed } \\
\text { through mobile phones }\end{array}$ & $\begin{array}{l}\text { - only the non- } \\
\text { interactive } \\
\text { version can be } \\
\text { accessed } \\
\text { through mobile } \\
\text { phones }\end{array}$ \\
\hline ODK & $\begin{array}{l}\text { Suite of tools for data } \\
\text { collection using mobile } \\
\text { devices. } \\
\text { Used in a practical } \\
\text { exercise. }\end{array}$ & $\begin{array}{l}\text { - allows data submission to an } \\
\text { online server } \\
\text { - enables building the skills needed } \\
\text { to: design a survey, collect data, } \\
\text { perform basic analysis } \\
\text { - can be used without an Internet } \\
\text { connection } \\
\text { - creating data collection forms } \\
\text { using spreadsheets deepens } \\
\text { logical skills }\end{array}$ & \\
\hline $\begin{array}{l}\text { Statistical } \\
\text { software }\end{array}$ & $\begin{array}{l}\text { Instat, used to perform } \\
\text { the exercises included in } \\
\text { eSMS. } \\
\text { Excel/ Open Office used } \\
\text { to analyse the data } \\
\text { collected through ODK. }\end{array}$ & $\begin{array}{l}\text {-enable building data analysis } \\
\text { skills } \\
\text {-pivot tables and charts enable to } \\
\text { easily manipulate and describe } \\
\text { data and assess trends and } \\
\text { relationships between numbers }\end{array}$ & $\begin{array}{l}\text { - due to limited } \\
\text { access to laptops } \\
\text { and personal } \\
\text { computers this } \\
\text { was used by a } \\
\text { limited number } \\
\text { of students }\end{array}$ \\
\hline
\end{tabular}

Table 1: Tool benefits and limitations. 
Overall, the use of e-SMS and CAST eased students' understanding of the concepts, and therefore their ability to apply them in their research and work. These tools enabled the students to experience effectively independent learning, while also prompting sharing and collaboration.

This was the first time e-SMS -designed as an e-learning course- was used entirely in faceto-face teaching. As discussed earlier, the students requested to meet for six instead of four hours per week to discuss concepts further and carry out exercises; this, and the degree of students' participation and interactions in class - in an environment where students are usually simply taking notes - were considered as indicators of the success of this experiment.

As mentioned above, e-SMS and CAST were used by the lecturer in class by mean of a laptop and a projector. Since all materials had been previously downloaded and could be used offline this ensured that the sessions were not disrupted by slow or absent internet connectivity. Further, to face power cuts which are especially frequent during the rainy season and which make it impossible to use a projector, the students were accessing regularly both e-SMS and CAST through their mobile phones, after downloading the materials and the required applications. Their use on mobile phones contributed to promote and foster collaboration, while enabling a personalised learning experience.

However, only the non-interactive version of CAST could be used by students on phones, due to the fact that the interactive material in CAST is written in Java and Android does not support Java. This was a major limitation to most of CAST.

ODK provided the students with practical experience while also deepening their logical and analytical skills, and through designing surveys and collecting data the students learnt a wide range of research methods skills, and about survey design, data quality, and measurement technique. Due to low access to laptops and personal computers the use of statistical software was limited, and both eSMS exercises and the analysis of the data collected through ODK were performed by a small number of students only.

The class created also a Whatsapp group which was used throughout the term and up to the exam to share knowledge and experiences, and to continue and support the learning out of class. The author used it to prompt discussions and regularly post questions and problems that would enable internalising the topics discussed in class (this included questions like the following: "Consider the income distribution of the Kenyan population: which one is higher, the mean income or the income of the median Kenyan?"). The use of this tool was well received as shown by the degree of interactions between students and with the lecturer. Further, following this experience, many students claimed to be using their mobile phones for educational purposes for the first time.

\section{CONCLUSION}

There are open tools based on Information and Communication Technologies and on an applied approach that can be used to transform research methods teaching. Overall, the use of such tools can ease students' understanding of the concepts, and their ability to apply them in their research and work, providing them with the practical skills required in the field of development. These tools can be used in resource-poor environments like Kenya, where relatively few students have access to laptops or computers and the internet connectivity is relatively low, but most have access to mobile devices.

The experience discussed in this paper was a one-year experiment, and although it can be considered successful under several aspects, some challenges remain and limit its sustainability and scalability. These challenges pertain first to the lack of computer facilities in the university, which can be overcome to some extent through the use of mobile devices. Other challenges pertain to resistance to change, by the lecturers and by the same students. Lecturers have a heavy workload which limits their ability and willingness to undertake the work required to transform the teaching and therefore prefer imparting a theory-based course, where they feel more confident and in control. Unfortunately there are no easy solutions to this challenge, except for the university to support staff training.

The resistance by the students is of two sorts. There are students who do not have access to the technology and oppose its use in the teaching; and there are students who are accustomed to the traditional teaching methods and to memorise concepts to pass the exam, and are therefore not willing to make the effort. Increasing cooperation between students could help overcoming resistance by 
both these groups. If students were to cooperate more, then they could share technology and make learning easier by working together. Unfortunately, individualism and lack of cooperation between students are deeply rooted in cultural tribalism and even rivalry between students belonging to the same tribe, and these have serious implications in terms of personal advancement in higher education institutions as well as in the workplace.

Although this is a complex problem, encouraging the use of technology in class, and particularly of mobile phones can foster a culture of collaboration. Mobile technologies are more and more accessible and relatively cheaper than laptops or personal computers, and enable doing more and more things. Using mobile technology in class could help creating a culture of sharing and cooperation that would benefit the students also later on in life.

\section{REFERENCES}

Manyalla, B., Mbasu, Z., Stern, D., \& Stern, R. (2014). Measuring the effectiveness of using computer assisted statistics textbooks in Kenya. In K. Makar, B. de Sousa, \& R. Gould (Eds.), Sustainability in Statistics Education. Proceedings of the Ninth International Conference on Teaching Statistics (ICOTS9), Flagstaff, Arizona, USA. Voorburg, The Netherlands: International Association for Statistical Education.

Stern, D., Stirling, D., \& Stern, R. (2009). Improving the learning of statistics with computer based exercises. IBS SUSAN Conference Proceedings.

Stern, D., Stirling, D., Dale, I., \& Stern, R. (2010). The use of computer-based tests to consolidate statistical concepts in Kenya. In C. Reading (Ed.), Proceedings of 8th International Conference on Teaching Statistics, Ljubljana, Slovenia. Voorburg, the Netherlands: ISI.

Stirling, D. (2005). CAST for Africa. Retrieved August 23, 2010, from CAST: http://cast.massey.ac.nz/collection_african.html 